\title{
Autonomy, Affiliation, and Ability: Relative Salience of Factors that Influence Online Learner Motivation and Learning Outcomes
}

\author{
Kuan-Chung Chen* \\ Graduate School of Education, Chung-Yuan Christian University, \\ Chung-Li 32023, Taiwan \\ E-mail: siderali@gmail.com \\ *Corresponding author

\section{Syh-Jong Jang*} \\ Graduate School of Education, Chung-Yuan Christian University, \\ Chung-Li 32023, Taiwan \\ E-mail: jang@cycu.edu.tw \\ *Corresponding author
}

\section{Robert Maribe Branch}

Educational Psychology and Instructional Technology, 630 Aderhold Hall, The University of Georgia, Athens, Georgia 30602, USA

E-mail: rbranch@uga.edu

\begin{abstract}
Autonomy, affiliation, and ability appear as main factors that influence online learners' motivation and learning outcomes, however, the relative salience of these three factors remains unclear in the online learning literature. Drawing on Deci and Ryan's self-determination theory, this study sought to bridge this gap by investigating the relative salience of perceived autonomy, affiliation, and ability on learner motivation and learning outcomes in two special education online programs $(N=262)$. This study found that the most salient predictor varied from categories of motivation and learning outcomes, and the number of significant predictors increased by participants' level of motivation/self-determination. Results of this study provide implications for online learner support.
\end{abstract}

Keywords: Online Learning, Motivation, Self-determination Theory, Student Support, Instructional Strategies.

Biographical notes: Kuan-Chung Chen is currently a post-doctorate researcher at the Chung Yuan Christian University in Taiwan. He received his $\mathrm{PhD}$ in Instructional Technology from the University of Georgia in 2009. With years of experience managing and supporting online certificate programs, he focuses his research on student motivation in the online learning environment. Particularly, he is interested in instructional support strategies that motivate online and distance learners. 
Syh-Jong Jang is Professor at the Graduate School of Education \& Center for Teacher Education, Chung Yuan Christian University in Taiwan. He received his $\mathrm{PhD}$ in Science Education from the University of Texas at Austin. His expertise is PCK, Technology in Teacher Education \& Innovative science teaching.

Robert Maribe Branch is Professor and Head of the Department of Educational Psychology and Instructional Technology at The University of Georgia. He completed his doctoral degree in 1989 at Virginia Tech. Dr. Branch is a former Fulbright Lecturer/Researcher to the University of KwaZulu-Natal, South Africa and an invited discussant to the 20th Annual Oxford Roundtable at Oxford University in England. He is co-editor the Educational Media and Technology Yearbook and author of Instructional Design: The ADDIE Approach. Dr. Branch's published research focuses on diagramming complex conceptual relationships and other complicated flow processes.

\section{Introduction}

Online learning has grown tremendously in recent years. The Sloan Consortium's report (Allen \& Seaman, 2006) indicated that more than $96 \%$ of large educational institutions $(15,000+$ enrollments $)$ in the United States offered online learning options. The growth trend for students enrolled in online courses is estimated to be around $40 \%$ per year over the next decade (Peltier, Schibrowsky, \& Drago, 2007). Online learning has become an important part of the education system.

Online learning's most distinguishing feature is its ability to liberate education from the constraints of time and distance (Collins \& Berge, 1995). In face-to-face classrooms, teachers and students meet in a physical location at a fixed period of time, while much of online learning happens in cyberspace, in which students can access learning materials anytime and anywhere. Another feature is that online learning relies on computer programs to mediate course materials and interactions, whereas people interact directly in face-to-face classroom settings. The distinctions of time, space, and ways of communication have, indeed, substantially changed the way people learn, for example, the online environment further allows for distributed forms of learning (Dede, 1996; Locatis \& Weisberg, 1997). Course events that have unfolded centrally in face-toface classrooms are now distributed across instructors and learners online. Therefore, "learning can occur at the same time in different places (e.g., through scheduled video conferencing events ... or at different times in different places (e.g., using email to communicate with the instructor and with one another" (Dabbagh \& Bannan-Ritland, 2005 , p. 11). Distributed learning enables diverse ways of learning in the online environment.

Nevertheless, online learning has a high student attrition rate. High attrition rates seem counterintuitive for an online learning environment where access and flexibility are featured components of instruction. While persistence at learning tasks serves as a key indicator of motivation (Pintrich \& Schunk, 2002), attrition reflects the need to investigate motivational issues of online learning (Keller, 1999), including factors that influence online learners' motivation and learning outcomes.

A theoretical framework useful for investigating online learners' motivation and learning outcomes is Deci and Ryan's $(1985,2002)$ self-determination theory (SDT). Pintrich and Schunk (2002) described SDT as "one of the most comprehensive and 
empirically supported theories of motivation available today" (p.257). Selfdetermination theory proffers that autonomy, relatedness, and competency are three determinants of motivation and well-being. A review of literature further showed that issues and themes in online learning corresponded with SDT's three determinants. In the following sections we first debrief the tenets of self-determination theory, then, we present the literature review of issues/themes in online learning that correspond with SDT's three factors: autonomy, relatedness, and competency.

\section{Self-Determination Theory}

Self-determination theory is a general theory of motivation that systematically explains the interrelationships among contextual support, motivation, and individuals' psychological well-being. The term self-determination, as defined by Deci and Ryan (1985), is "the capacity to choose and have those choices ... be the determinants of one's actions" (p. 38). Self-determination theory proffers that humans' psychological growth and integration are facilitated through the satisfaction of three universal basic needs: the need for autonomy (a sense of control and agency), the need for competency (feeling competent with tasks and activities), and the need for relatedness (feeling included or affiliated). Individuals experience an elaborated and unified sense of self, embrace selforiented motivation, and achieve a better sense of well-being through the satisfaction of autonomy, competency, and relatedness (Ryan \& Deci, 2002). Conversely, the deprivation of the three basic needs produces highly fragmented, reactive, or alienated selves.

Contrasting several other motivational theories that treat human motivation as a monolithic construct, self-determination theory posits three main types of motivation: intrinsic motivation (doing something because it is enjoyable, optimally challenging, or aesthetically pleasing), extrinsic motivation (doing something because it leads to a separable outcome) and amotivation (the state of lacking intention to act). Extrinsic motivation is further categorized into four stages/types:

1. External regulation, whereby individuals behave in order to obtain rewards or avoid punishment;

2. Introjected regulation, whereby individuals introject the tasks into internal "ought" or "should" motives and usually feel guilty or anxious;

3. Identified regulation, whereby individuals recognize the tasks as personally important but are still motivated externally; and,

4. Integrated regulation, whereby individuals integrate various sources of information into their self-schema.

The above-mentioned types of motivation, as shown in Figure 1 (Ryan \& Deci, 2000), are loaded on a continuum of self-determination. Amotivation represents the least selfdetermined type of motivation while intrinsic motivation signifies the most selfdetermined type of motivation. Contextual supports of autonomy, affiliation, and ability help individuals internalize extrinsic goals and values into the self. During internalization, individuals become more assured and self-determined, and achieve enhanced well-being. 


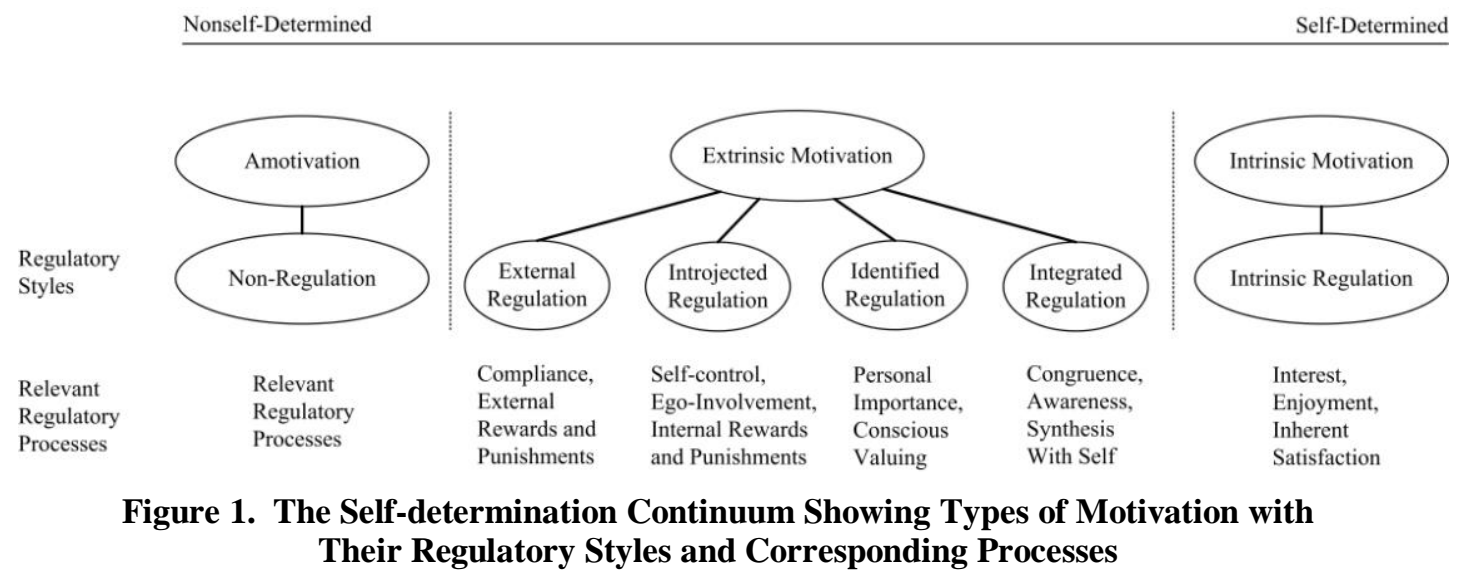

\section{Factors Influencing Online Learner Motivation and Learning Outcomes}

In the online and distance learning literature, many research areas or issues have been associated with student motivation and learning outcomes. This section synthesizes the most frequently cited issues, as thematically grouped into three factors: 1) autonomy, 2) affiliation, 3) ability.

\subsection{Autonomy}

Flexible learning, learner autonomy, and learner control share the common theme of autonomy. Brande (1994) defined flexible learning as "enabling learners to learn when they want (frequency, timing, duration), how they want (modes of learning), and what they want (that is learners can define what constitutes learning to them)" (p. 2). A similar definition was given to learner control: "learners make their own decisions regarding some aspect of the 'path,' 'flow,' or 'events' of instruction" (Williams, 1996, p. 957). Regarding learner autonomy, Moore (1993) defined it as "the extent to which in the teaching/learning relationship it is the learner rather than the teacher who determines the goals, the learning experiences, and the evaluation decisions of the learning programme" (p. 31).

The common ground underlying flexible learning, learner autonomy, and learner control is that learners are capable of exerting control over their own learning processes, thereby aligning learning pace with learning style. Autonomous learners also assume higher responsibility for their learning, which requires self-direction and self-regulation (Rovai, 2003). The interrelationships among autonomy, flexibility, and learner control are illustrated in Figure 2.

The autonomy category, which includes flexible learning, learner autonomy, and learner control, is closely related to online learners' motivation. The online learning environment renders flexibility of time and space, allowing for people who are distant, busy, or physically disabled to participate in class. Furthermore, online learning increases accessibility. Course materials and conversations can be accessible to students at a later time, enabling continued discussions and deeper reflections on given topics (Reed, 2000). Students can also retrieve virtually limitless resources online, access a variety of computer-based learning tools such as simulations and games, or collaborate with experts and students worldwide (Riel \& Harasim, 1994). The flexible nature of online learning has frequently been reported as the most motivating factor for online 
students (Kim, Liu, \& Bonk, 2005; Morrison, Sweeney, \& Heffernan, 2004; Peltier et al., 2007). For example, one student interviewed for a newspaper report by Carr (2000) described flexibility of time as the most significant motivating factor, "I really think that distance education is a great opportunity for someone who has either a tough professional schedule or a tough personal schedule to continue their education" (II 26).

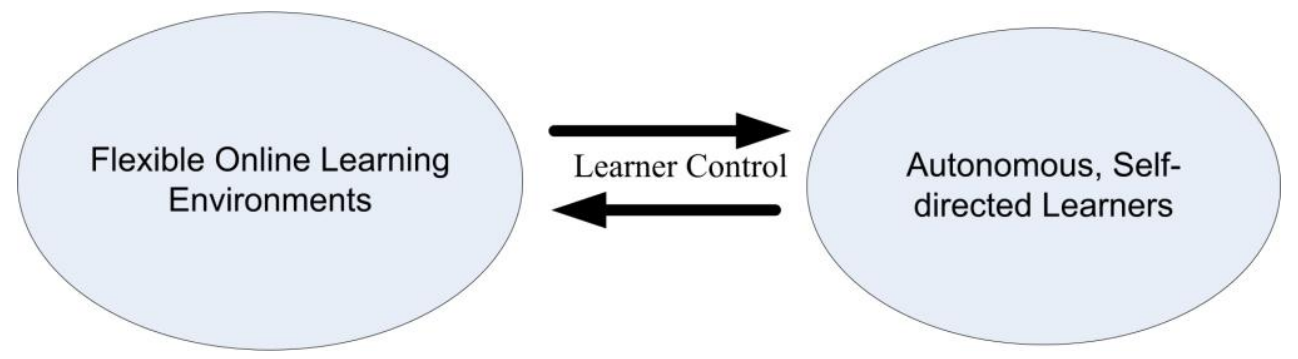

Figure 2. The Interrelationships among Autonomy, Flexibility, and Learner Control

Regarding the effects of learner autonomy on student motivation and learning outcomes, Drennan, Kennedy, and Pisarki (2005), drawing on Davis, Bagozzi, and Warshaw's (1989) Technology Acceptance Model (TAM), explored the relationships between students' locus of control, perceived usefulness/ease of use of flexible learning, and course satisfaction. Using structural equation modeling, Drennan et al. found a positive and direct relationship between students' locus of control and course satisfaction, meaning that those students who believe they have control over their learning enjoy higher levels of course satisfaction than those who do not. A positive and direct path was also found between locus of control and perceived usefulness of flexible learning.

Similar results were found in Chou and Liu's (2005) 14-week field experiment. In Chou and Liu's study, a technology-mediated virtual learning environment (TVLE) was developed with a focus on enhanced learner control. Chou and Liu found that students in the TVLE group achieved better, attained higher computer self-efficacy, were more satisfied, and experienced a better learning climate than those in the face-to-face classroom group. Xie, Debacker, and Ferguson (2006), in their study of online discussions, found a negative effect of instructor control. Students' motivation decreased due to mandatory participation in online discussions.

\subsection{Affiliation}

Although online learners have often been labeled as autonomous or independent learners, this is not to say that online learners do not need to affiliate with others. Quite the opposite: online learners' affiliation has long been acknowledged as a critical factor influencing their learning success (Dennen, Darabi, \& Smith, 2007; Hara \& Kling, 2000; Wegerif, 1998). On the cognitive side, affiliation/social interaction may expand learners' perspectives, deepen their thoughts, and resolve learning problems beyond an individual's capacity. On the affective side, affiliation promotes learners' feelings of belongingness, and increases their motivation to learn. In the online learning literature, issues revolving around student affiliations include social interaction, social presence in computer-mediated communication (CMC), student isolation, and students' sense of community. This section synthesizes these issues, with a focus on students' motivation. 
Face-to-face interactions, an essential and inseparable element in traditional classrooms, are substituted by computer-mediated communications in the online learning environment. Given this fact, online learning has been charged with being cold, impersonal, and demotivating (Galusha, 1997). Dabbagh and Bannan-Ritland (2005) stated:

Although several telecommunications technologies such as audio- and videoconferencing have enabled a simulated human interaction learning context, the absence of face-to-face interaction in classic distance education settings has been identified as one of the main causes of loss of student motivation. (p. 6)

Moreover, a large portion of online communication is text-based (Jang, 2008; Lapadat, 2002; Tu, 2002). When the primary communication medium is written text, resolving ambiguities in communications becomes more difficult than in face-to-face encounters (Hara \& Kling, 2000).

Because of the limitations of computer-mediated communication, enhancing social interaction becomes an even more important issue in the online learning environment. Kreijns, Kirschner, and Jochems (2003), however, identified two pitfalls commonly found in computer-mediated learning environments: 1) educators taking for granted that social interactions automatically happen; 2) educators focusing on the cognitive effects of social interactions while ignoring socio-emotional processes. Kreijns et al. suggested four ways to promote social interactions: 1) using collaborative learning methods; 2) building interactivity into computer-supported learning environments; 3) adapting student-centered pedagogies; and, 4) increasing students' feeling of social presence. Notably, the authors emphasized the importance of non-task activities (e.g., informal and casual conversations), as these activities better contribute to impression formation, cultivation of social relationships, and nurturing a sense of community than task-based activities. Howland and Moore (2002) suggested that instructors provide timely and adaptive feedback based on task difficulty and individual student's needs, maintain periodic correspondence to keep students connected and engaged, and arrange optional face-to-face activities if possible.

Empirical studies have shown that social interaction and student affiliation significantly impacts student motivation and learning outcomes (Gao \& Lehman, 2003; Marks, Sibley, \& Arbaugh, 2005; Wegerif, 1998). Wegerif, for example, found that students who felt themselves insiders of the learning community evaluate themselves as being successful and benefited most from class. Conversely, those outsiders tend to feel anxious, defensive, and unwilling to take risks involved in learning. An online instructor interviewed for Carr's (2000) article in the Chronicle of Higher Education reported that his course-completion rates jumped from 62 percent to 90 percent when he switched to a more interactive online system and started to efficiently manage student correspondence.

Gao and Lehman (2003) conducted a field experiment to investigate levels of social interaction and college students' motivation and achievement. Two experimental groups were assigned. Students in the reactive interaction group received elaborated immediate feedback, while those in the proactive interaction group were required to participate in generative activities. The control group only received static hyperlinks of the course content. Results showed that students in both the reactive and proactive interaction groups achieved better than those in the control group. Moreover, students in the reactive interaction group revealed higher motivation to learn than the control group. Marks, Sibley, and Arbaugh (2005) studied different types of interactions. Drawing on Moore's (1989) typology of interaction, Marks et al. examined interaction-related constructs and their effects on students' perceived learning. Using structural equation 
modeling, Marks et al. found that instructor-student interactions and student-student interactions stood out as the most significant predictors of perceived learning, while most content-related constructs were non-significant. Notably, instructor-student interactions were much more salient than student-student interactions in predicting perceived learning, with the path coefficient twice as much as student-student interactions. Gao and Lehman's, and Marks et al's studies suggest that social interactions are essential to online learners' motivation and learning outcomes. Instructors should first emphasize their interactions with students, and then adopt strategies such as encouraging discussion and providing feedback in their online instruction.

\subsection{Ability}

Ability is the third theme relating to online learners' motivation. Online learning imposes greater requirements for a variety of skills, regarding technology, collaborative learning, and self-regulation (Dabbagh \& Bannan-Ritland, 2005). With regards to technological skills, computer operation, software installation, and troubleshooting often accompany online course activities. Web browsing, data searching, and file management are also integral to online learning. Some course activities require greater technical skill, as applied to using software for design work, for example.

Furthermore, for synchronous and asynchronous communications, collaborative learning skills are indispensable. Dabbagh and Bannan-Ritland (2005) listed four categories of collaborative learning skills: 1) social learning skills, 2) discursive, or dialogic, skills, 3) self- and group evaluation skills, and 4) reflection skills. Joined with autonomy in online learning is self-directed learning. This requires developing a variety of cognitive and metacognitve strategies, such as organizational strategies, self-awareness, and self-regulation (Howland, \& Moore, 2002; Olgren, 1998). Lastly, as mentioned earlier, a majority of online communication is presented in written format (Lapadat, 2002; $\mathrm{Tu}, 2002)$. The text-based property of online communication challenges online learners' communication and writing skills (Yang, Tsai, Kim, Cho, \& Laffey, 2006). In view of a variety of skills required for online learning, Vonderwell and Zachariah (2005) suggested that "students need to be prepared for technology, learning management, pedagogical practice, and the social roles" (p. 225).

Many frustrations of online learners are ability-related, among which technical issues and information overload are most frequently reported. Song, Singleton, Hill, and Koh (2004) found technical problems to be the biggest barrier for online learners, as was expressed by $58 \%$ of their participants. Howland and Moore (2002) found that online learning technologies, such as the discussion board, were challenging for novice students. When students feel incompetent using technologies, or when they encounter technical problems without timely help, they feel anxious, awkward, and distressed (Motteram \& Forrester, 2005; Xie et al., 2006). Tait (2003) stated that the technical issue is one of the main reasons students drop their online courses.

Another frequently cited problem is information overload, which refers to the situation in which a person's intended cognitive processing exceeds his/her available cognitive capacity (Mayer \& Moreno, 2003). Armatas et al. (2003) reported that many online students were overwhelmed by the variety of resources and were confused about what they should prioritize. Online discussions and email messages also overwhelm students, as illustrated by an online student's report: "I don't really like turning on the computer and finding that I have eleven messages on my e-mail. It's a pain ... that is just time-consuming, but it is a part of at a distance" (Hara \& Kling, 2000, II 57). Clearly, students need guidance to prioritize relevant resources, as well as to develop strategies to manage information. 
Lim (2001), Thompson, Meriac and Cope (2002), Conrad (2002) and Armatas et al. (2003) have shown that online students' perceived ability is a strong predictor of motivation and learning outcomes. In an effort to build a model of online learning satisfaction, Lim surveyed 235 online learners across five universities. Multiple regression analysis revealed that computer self-efficacy was a strong predictor of learning satisfaction, as well as participants' motivation to take future web-based courses. Thompson, Meriac, and Cope also found a positive correlation between online students' self-efficacy and their performance on online data search.

Prior experience, a factor closely related to ability, has been related to online learners' motivation. Conrad (2002) found that students with more online learning experience were less anxious about online learning. Armatas et al. (2003) reported students' attitudes change with experience. Students were confused and disgruntled at the beginning of the semester; however, once students became familiar with the learning environment they began to enjoy their online learning. The results of Conrad and Armatas et al.'s studies suggest that supporting online learners' self-efficacy and experiences provide a pathway to student success.

The contention here based on the above literature review is that selfdetermination theory may serve as an appropriate framework for addressing motivation in online learning. SDT's three determinants (autonomy, relatedness, and competency) align with main themes of online learner motivation: autonomy, affiliation, and ability. Established from past experiments, self-determination theory predicts a variety of learning outcomes, including performance, persistence, and learning satisfaction (Deci \& Ryan, 1985). Self-determination theory has the potential to address learning problems such as student attrition in the online learning environment.

\section{Relative Salience of Autonomy, Affiliation, and Ability: A Research Gap}

A research gap was identified after reviewing the online and distance learning literature: most studies individually assessed the effect of a certain theme/factor, such as learner autonomy, on students' motivation and learning outcomes. However, still there is a lack of a "big picture" illustrating how the themes (autonomy, affiliation, and ability) together influence online learners' motivation and learning outcomes. In particular, the relative salience of autonomy, affiliation, and ability on learner motivation and learning outcomes remain unclear. Because "the whole is more than the sum of its parts" (Bertalanffy, 1972), studies examining the interrelationships among these themes can better our understanding about the dynamics among learner motivation, learning outcomes, and their contributing factors in the online learning context. Results from this line of research also help online educators prioritize resources for online learner support. Accordingly, this study intends to investigate the relative salience of autonomy, affiliation, and ability on online students' motivation and learning outcomes. Two research questions guide this study:

1. What is the relative salience of autonomy, affiliation, and ability on online learners' motivation?

2. What is the relative salience of autonomy, affiliation, and ability on online learners' learning outcomes? 


\section{Methodology}

\subsection{Participants}

Two hundred and sixty-seven (267) online students participated in this study. The students were enrolled in two special education online certificate programs at a large research university in the southeastern United States. The two online programs share similar course work. The online courses are hosted on the WebCT course management system, and utilize a live chat system (Wimba) and a variety of software, such as Adobe Reader and Real Player, to facilitate teaching and learning. Two hundred and sixty-two (262) cases were included in the datasets after removing outliers (using $z=3.5$ as the cutoff point). The majority of participants were female $(78.1 \%)$, making the male/female ratio approximately $1: 3.5$. Participants' age ranged from 19 to 65 , with the average of $37.80(S D=10.23)$. Table 1 presents participants' demographic characteristics in more detail.

Table 1: Demographic Characteristics of Participants

\begin{tabular}{llcc}
\hline \multirow{2}{*}{ Variable } & Subcategory & \multicolumn{2}{c}{$(n=262)$} \\
\cline { 3 - 4 } & & Valid $n$ & Valid \% \\
\hline Gender & Male & 57 & 21.9 \\
& Female & 203 & 78.1 \\
\hline Age & 29 and below & 68 & 26.3 \\
& $30-39$ & 86 & 33.2 \\
$40-49$ & 68 & 26.3 \\
& $50-59$ & 31 & 12.0 \\
& 60 and above & 6 & 2.3 \\
\hline
\end{tabular}

\subsection{Instrumentation}

\subsubsection{Perceived Autonomy, Affiliation, and Ability}

Three previously validated questionnaires were used to assess online students' perceived autonomy, affiliation, and ability. The Perceived Autonomy Scale was adapted from the Standage, Duda, and Ntoumanis (2005) study. The scale contains six items. Each item has been modified to fit the research context. A sample item is "In this course I can decide which activities I want to participate." A reliability test on the six-item Perceived Autonomy Scale revealed an acceptable internal consistency $(\alpha=.69)$.

To assess participants' perceived affiliation, South's (2006) Sense of Community Instrument was adopted. The instrument was designed for an online continuing education program, similar to the context of this study. After reviewing each subscale of the inventory, we determined that trust, interactivity, and shared values were more relevant to this study. A total of nine items were extracted from the subscales, of which a sample item is "I feel that my classmates care about each other." A reliability test on the nine-item Perceived Affiliation Scale revealed a satisfactory internal consistency $(\alpha=.86)$. 
Perceived ability was measured by the Perceived Competence Scale, which was retrieved from SDT's official website (http://www.psych.rochester.edu/SDT/measures/ index.html). The Perceived Competence Scale contains six items. The stems have been slightly modified to fit the research context. A sample item is "I am satisfied with my performance in this online course." A reliability test on the six-item Perceived Competence Scale revealed a satisfactory internal consistency $(\alpha=.86)$.

\subsubsection{Motivation}

We used Vallerand et al.'s (1992) SDT-based Academic Motivation Scale (AMS) to measure student motivation. The AMS is made up of seven subscales each contains 4 items, for which intrinsic motivation has been further categorized into intrinsic motivation to know, to accomplish, and to experience stimulation, totaling three subscales with twelve items. For the purpose of this study, the categorization of intrinsic motivation was not adopted. The twelve items were treated as presenting a single construct: intrinsic motivation.

Amotivation and three types of extrinsic motivation - external, introjected, and identified regulations - were also measured by the Academic Motivation Scale. A reliability test based on the data of this study indicated that AMS has satisfactory internal consistency across subscales, ranging from .77 to .96. Vallerand et al. (1992) further demonstrated that the AMS has an appropriate test-retest reliability over a month period $(\mathrm{r}=.79)$.

\subsubsection{Leaning Outcomes}

Four categories of learning outcomes were gathered, including 1) engagement, 2) achievement, 3) perceived learning, and 4) course satisfaction. Student engagement was assessed using both self-report and objective measures. The self-report measure refers to a questionnaire item asking "How many hours per week did you devote to this course?" The objective measure includes online students' number of hits, referring to the number of times that students accessed WebCT content pages. The number of hits data was gathered through the "track student" function of WebCT.

Student achievement was assessed using both self-report and objective measures. The self-report measure is presented by students' expected grade, gathered from a questionnaire item asking "What grade do you expect to get for this course?" Possible responses for the expected grade item include A, B, C, D, F, and Incomplete. The objective measure includes online students' final grade, which was loaded on a 0-100 scale.

Participants' perceived learning was measured using Alavi's (1994) six-item Perceived Learning Scale, of which a sample item is "I learned to inter-relate the important issues in the course material." The scale has been reported to yield a high internal consistency, ranging from .92 to .95 (Gomez Alvarez, 2005). A reliability test based on the data of this study also yielded a high internal consistency $(\alpha=.95)$.

As with course satisfaction, this study adopted Hao's (2004) Online Course Satisfaction Survey, which evaluates "the general course satisfaction of the online students" (Hao, 2004, p. 47). The survey has ten items, of which a sample is: "Overall, I am satisfied with this course." The items have been modified to fit the research context. A reliability test on the ten-item Course Satisfaction Survey revealed a satisfactory internal consistency $(\alpha=.93)$. 


\subsection{Procedure}

At the outset of this study, the researchers communicated with the program administrators and course instructors to make sure that they fully understood the purpose and logistics of this study. The researchers also sought and obtained support from the administrators' and instructors to encourage student participation. Because participants were geographically dispersed, an online survey (see Figure 3 for a snapshot) was developed and distributed through SurveyMonkey, a commercial website for surveys. The online survey collected self-report data, including demographics, perceived autonomy, affiliation, and ability, motivation, and learning outcomes. Objective data, including students' final grades and the numbers of hits were gathered separately through the assistance of the program secretary. Data collection proceeded at the end of the summer term in 2008 and lasted for ten days.

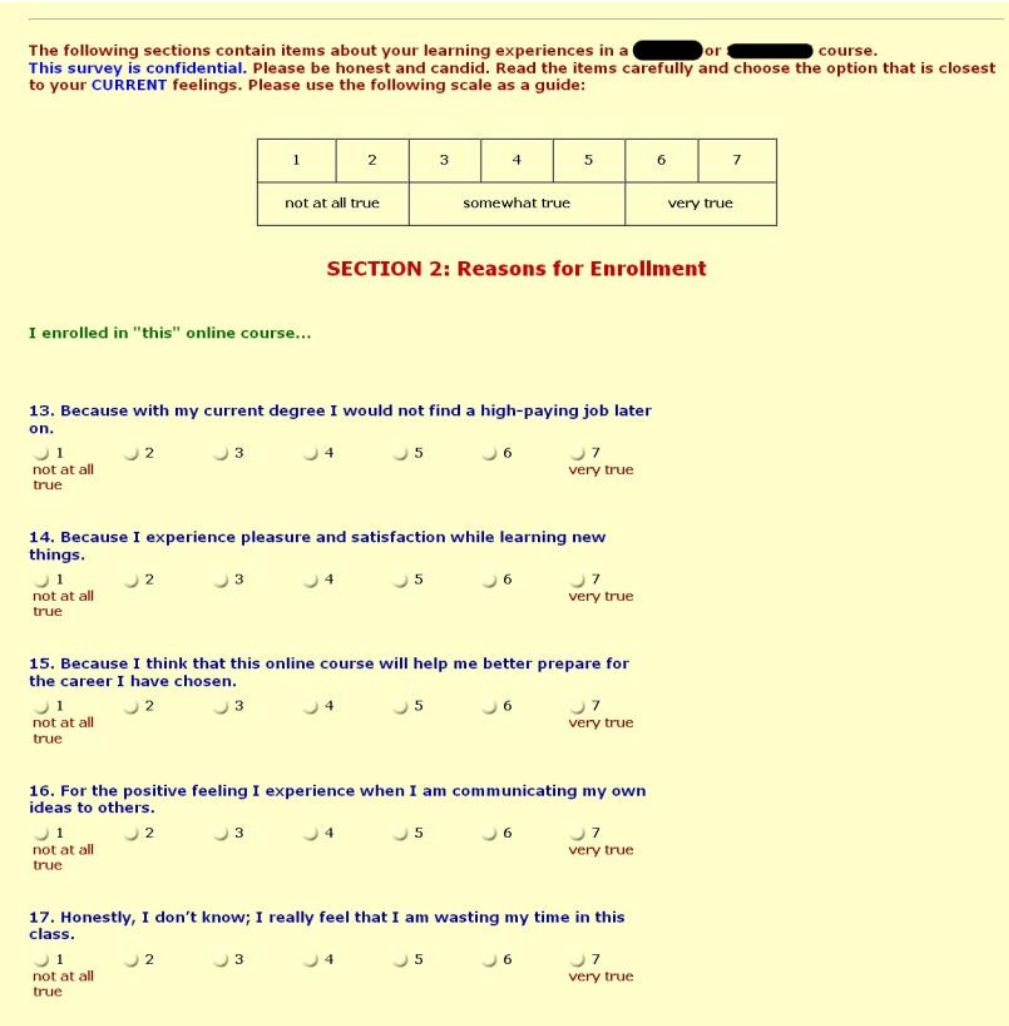

Figure 3. The Online Survey

Simultaneous multiple regression was used to test the relative salience of students' perceived autonomy, perceived ability, and perceived affiliation. The dependent variables included the five types of motivation and the six learning outcomes: 1) hours per week studying, 2) number of hit, 3) expected grade, 4) final grade, 5) perceived learning, and 6) course satisfaction. Collinearity was checked in each multiple regression analysis. None of the predictive variables exceeded the threshold of 10 for the variance inflation factor (VIF). Regarding the overall regression model, none of the 
analyses revealed a condition index $(\mathrm{CI})$ value greater than 30 . The above results indicated that there were no severe collinearnality among variables. Below is a detailed report of the relative salience of perceived autonomy, ability, and affiliation on online learners' motivation and learning outcomes.

\section{Results}

\subsection{The Relative Salience of Perceived Autonomy, Ability, and Affiliation on Online Learners' Motivation}

\subsubsection{Amotivation}

A simultaneous regression indicated that participants' perceived ability had the highest (in absolute value) standardized regression coefficient $(\beta=-.275)$ when predicting amotivation, followed by perceived affiliation $(\beta=-.154)$ and perceived autonomy $(\beta=$ -.116). Therefore, the relative salience (order) of students' perceived autonomy, affiliation, and ability on amotivation is:

1. Perceived ability

2. Perceived affiliation

3. Perceived autonomy

Furthermore, perceived ability $(t=-4.46, p<.001)$ and perceived affiliation $(t=$ $-2.38, p<.05)$ significantly and negatively predicted amotivation. The total $R^{2}$ was .170 , and the adjusted $R^{2}$ was .164 , which means that the two predictors explained $16.4 \%$ of the variance of amotivation.

\subsubsection{External Regulation}

A simultaneous regression indicated that participants' perceived autonomy had the highest standardized regression coefficient $(\beta=.232)$ when predicting external regulation, followed by perceived affiliation $(\beta=.079)$ and perceived ability $(\beta=.033)$. Therefore, the relative salience of students' perceived autonomy, affiliation, and ability on external regulation is:

1. Perceived autonomy

2. Perceived affiliation

3. Perceived ability

Furthermore, only perceived autonomy $(t=3.41, p<.001)$ significantly predicted external regulation. The total $R^{2}$ was .077 , and the adjusted $R^{2}$ was .074 , which means that perceived autonomy explained $7.4 \%$ of the variance of external regulation.

\subsubsection{Introjected Regulation}

A simultaneous regression indicated that participants' perceived autonomy had the highest standardized regression coefficient $(\beta=.399)$ when predicting introjected regulation, followed by perceived ability $(\beta=.112)$ and perceived affiliation $(\beta=.08)$. Therefore, the relative salience of students' perceived autonomy, affiliation, and ability on introjected regulation is:

1. Perceived autonomy

2. Perceived ability

3. Perceived affiliation 
Furthermore, only perceived autonomy $(t=6.45, p<.001)$ significantly predicted introjected regulation. The total $R^{2}$ was .222 , and the adjusted $R^{2}$ was .219 , which means that perceived autonomy explained $21.9 \%$ of the variance of introjected regulation.

\subsubsection{Identified Regulation}

A simultaneous regression indicated that participants' perceived autonomy had the highest standardized regression coefficient $(\beta=.308)$ when predicting identified regulation, followed by perceived affiliation $(\beta=.169)$ and perceived ability $(\beta=.107)$. Therefore, the relative salience of students' perceived autonomy, affiliation, and ability on identified regulation is:

\section{Perceived autonomy \\ 2. Perceived affiliation \\ 3. Perceived ability}

Furthermore, perceived autonomy $(t=4.89, p<.001)$ and perceived affiliation $(t$ $=2.65, p<.01)$ significantly predicted identified regulation. The total $R^{2}$ was .206 , and the adjusted $R^{2}$ was .200 , which means that the two predictors explained $20.0 \%$ of the variance of identified regulation.

\subsubsection{Intrinsic Motivation}

A simultaneous regression indicated that the participants' perceived autonomy had the highest standardized regression coefficient $(\beta=.425)$ when predicting intrinsic motivation, followed by perceived affiliation $(\beta=.175)$ and then perceived ability $(\beta$ $=.127$ ). Therefore, the relative salience of students' perceived autonomy, affiliation, and ability on intrinsic motivation is:

1. Perceived autonomy

2. Perceived affiliation

3. Perceived ability

Furthermore, perceived autonomy $(t=7.40, p<.001)$, perceived ability $(t=2.30$ $p<.05)$, and perceived affiliation $(t=3.02, p<.001)$ all significantly predicted intrinsic motivation. The total $R^{2}$ was .346 , and the adjusted $R^{2}$ was .338 , which means that the three predictors explained $33.8 \%$ of the variance of intrinsic motivation.

\subsection{The Relative Salience of Perceived Autonomy, Ability, and Affiliation on Online Learners' Learning Outcomes}

\subsubsection{Hours per Week Studying}

A simultaneous regression indicated that the participants' perceived autonomy had the highest standardized regression coefficient $(\beta=.112)$ when predicting participants' hours per week studying, followed by perceived affiliation $(\beta=.069)$ and perceived ability $(\beta$ $=.053$ ). Therefore, the relative salience of students' perceived autonomy, affiliation, and ability on hours per week studying is:
1. Perceived autonomy
2. Perceived affiliation
3. Perceived ability

Unexpectedly, none of the above three variables significantly predicted hours per week studying. The three variables together explained $2.3 \%$ of the variance of hours per week studying in the regression model. 


\subsubsection{Number of Hits}

A simultaneous regression indicated that the participants' perceived autonomy had the highest standardized regression coefficient $(\beta=.227)$ when predicting participants' number of hits, followed by perceived affiliation $(\beta=.115)$ and perceived ability $(\beta$ $=.005)$. Therefore, the relative salience of students' perceived autonomy, affiliation, and ability on number of hits is:

\section{Perceived autonomy \\ 2. Perceived affiliation \\ 3. Perceived ability}

Furthermore, only perceived autonomy $(t=2.63, p<.05)$ significantly predicted online students' number of hits. The $R^{2}$ was .074 , and the adjusted $R^{2}$ was .068 , which means that perceived autonomy explained $6.8 \%$ of the variance of number of hits.

\subsubsection{Expected Grade}

A simultaneous regression indicated that participants' perceived ability had the highest (in absolute value) standardized regression coefficient $(\beta=.471)$ when predicting expected grade, followed by perceived affiliation $(\beta=-.096)$ and perceived autonomy $(\beta$ $=-.017)$. Therefore, the relative salience of students' perceived autonomy, affiliation, and ability on participants' expected grade is:

1. Perceived ability

2. Perceived affiliation

3. Perceived autonomy

Furthermore, only perceived ability $(t=7.42, p<.001)$ significantly predicted expected grade. The $R^{2}$ was .185 , and the adjusted $R^{2}$ was .182 , which means that perceived ability explained $18.2 \%$ of the variance of participants' expected grade.

\subsubsection{Final Grade}

A simultaneous regression indicated that participants' perceived ability had the highest (in absolute value) standardized regression coefficient $(\beta=.215)$ when predicting participants' final grade, followed by perceived affiliation $(\beta=-.213)$ and perceived autonomy $(\beta=-.112)$. Therefore, the relative salience of students' perceived autonomy, affiliation, and ability on participants' final grade is:

1. Perceived ability

2. Perceived affiliation

3. Perceived autonomy

Furthermore, perceived ability $(t=2.59, p=.01)$ and perceived affiliation $(t=-$ $2.45, p<.05)$ significantly predicted final grade. The total $R^{2}$ was .075 , and the adjusted $R^{2}$ was .063 , which means that the two variables explained $6.3 \%$ of the variance of final grade.

\subsubsection{Perceived Learning}

A simultaneous regression indicated that participants' perceived ability had the highest standardized regression coefficient $(\beta=.376)$ when predicting perceived learning, followed by perceived affiliation $(\beta=.255)$ and perceived autonomy $(\beta=.204)$. Therefore, the relative salience of students' perceived autonomy, affiliation, and ability on perceived learning is: 
1. Perceived ability

2. Perceived affiliation

3. Perceived autonomy

Furthermore, perceived autonomy $(t=3.74, p<.001)$, perceived ability $(t=7.21$, $p<.001)$, and perceived affiliation $(t=4.64, p<.001)$ all significantly predicted perceived learning. The total $R^{2}$ was .414 , and the adjusted $R^{2}$ was .407 , which means that the three predictors explained $40.7 \%$ of the variance of perceived learning.

\subsubsection{Course Satisfaction}

A simultaneous regression indicated that participants' perceived affiliation had the highest standardized regression coefficient $(\beta=.549)$ when predicting course satisfaction, followed by perceived ability $(\beta=.190)$ and perceived autonomy $(\beta=.128)$. Therefore, the relative salience of students' perceived autonomy, affiliation, and ability on course satisfaction is:

1. Perceived affiliation

2. Perceived ability

3. Perceived autonomy

Furthermore, perceived affiliation $(t=10.90, p<.001)$, perceived ability $(t=$ $3.99, p<.001)$, and perceived autonomy $(t=2.56, p<.05)$ all significantly predicted course satisfaction. The total $R^{2}$ was .508 , and the adjusted $R^{2}$ was .503 , which means that the three predictors explained $50.3 \%$ of the variance of course satisfaction.

Table 2 presents a summary of the regression analyses discussed in this section. Three phenomena were discovered when we scanned through the summary table. First, the most salient predictor varied from categories of motivation and learning outcomes. Perceived autonomy was the most salient predictor for intrinsic and extrinsic motivation (including external, introjected and identified regulations); however, perceived ability was most salient for amotivation. Regarding learning outcomes, perceived autonomy was the most salient predictor for engagement (including hours per week studying and number of hits), while perceived ability was the most salient predictor for perceived learning and achievement (including expected grade and final grade). Interestingly, online students' course satisfaction was most predicted by perceived affiliation.

Secondly, the number of significant predictors increased by participants' level of self-determination. External and introjected regulations, which are less self-determined types of motivation, were predicted by only one factor, perceived autonomy. Identified regulation, a more self-determined type of motivation, was predicted by two factors: perceived autonomy and perceived affiliation. Intrinsic motivation, the most selfdetermined type of motivation, was predicted by all three factors: perceived autonomy, perceived affiliation, and perceived ability. Third, the variance of an outcome variable explained by significant predictors varied significantly, ranging from $6.3 \%$ to $50.3 \%$. Significant predictors explained more than $20 \%$ of the variance of intrinsic motivation (33.8\%), introjected regulation (21.9\%), and identified regulation (20.0\%). However, external regulation had a relatively low percentage of variance explained $(7.4 \%)$. Regarding learning outcomes, perceived learning $(40.7 \%)$ and course satisfaction $(50.3 \%)$ had the highest percentage of variance explained by significant predictors. On the other hand, the percentages for hours per week studying, number of hits, and final grade were all below $10 \%$. 
30 Knowledge Management \& E-Learning: An International Journal, Vol.2, No.1.

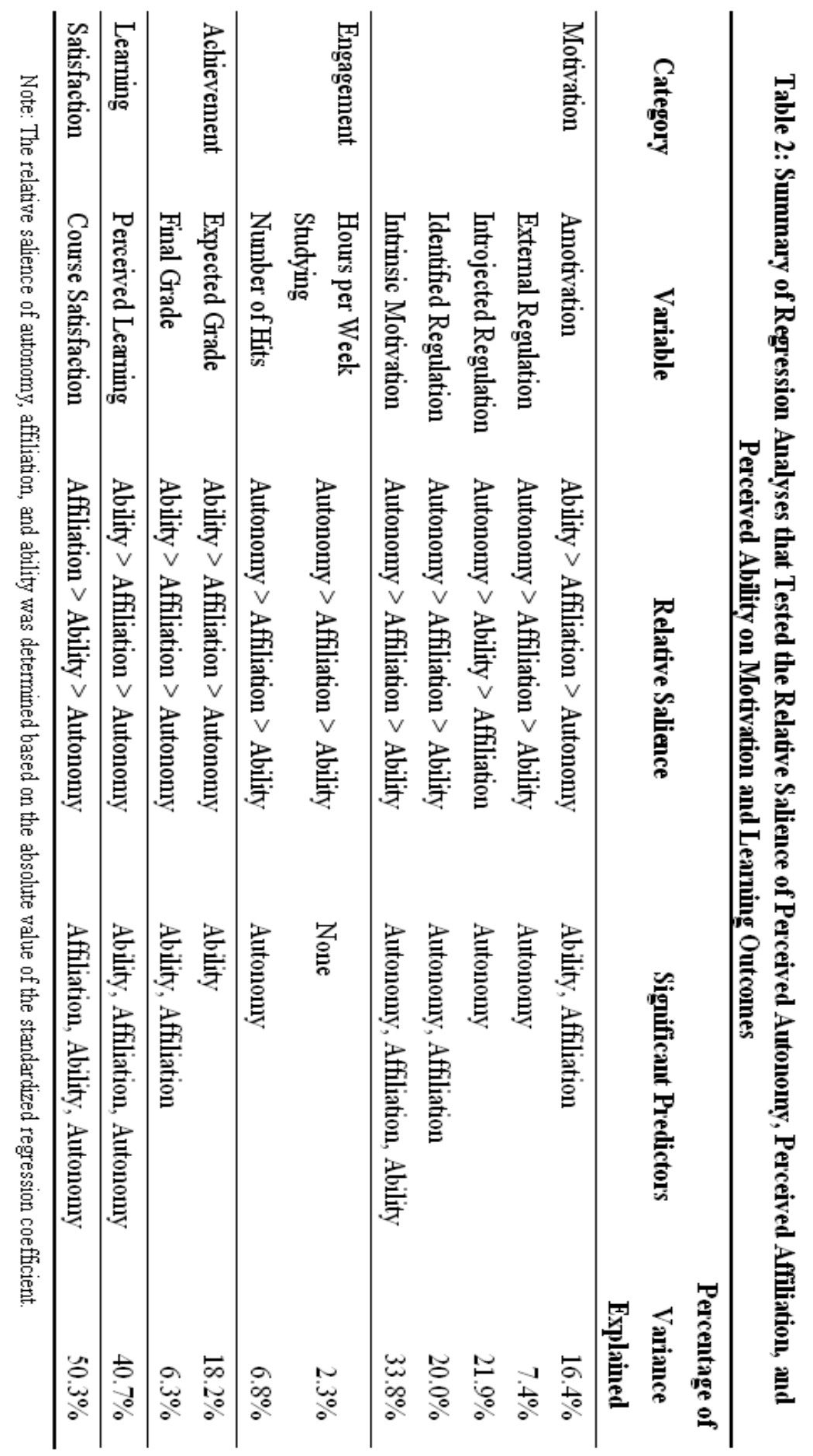




\section{Discussion}

This study examined the relative salience of perceived autonomy, perceived affiliation, and perceived ability on online students' motivation and learning outcomes. Regarding the motivation category, perceived autonomy stood out as the most significant factor that predicted online students' intrinsic and extrinsic motivations. Perceived ability, on the other hand, served as the most salient predictor of online learners' amotivation. The results provide important implications for online instruction: online learning practitioners should first address online learners' ability, such as providing technical orientations or consultations in order to avoid students becoming frustrated and amotivated, or even dropping out of class. Online learning practitioners should also adopt appropriate strategies that promote online learners' perceived autonomy to keep students motivated and engaged throughout their online study.

Furthermore, perceived affiliation was found to be the second salient factor that positively predicted online learners' identified regulation and intrinsic motivation, and negatively predicted amotivation. Therefore, online learning practitioners should create an interactive learning environment that fosters online learners' feelings of affiliation. As suggested by Song et al. (2004), instructors can embed community building strategies, such as encouraging collective reflection and devising small group case studies into their online course activities. Optional face-to-face activities were suggested by Howland and Moore (2002) to compensate for the lack of social presence and to promote a higher level of social engagement.

An interesting pattern was discovered in this study: external and introjected regulations, which are less self-determined types of motivation, were predicted by only one factor, perceived autonomy. Identified regulation, a more self-determined type of motivation, was predicted by two factors: perceived autonomy and perceived affiliation. Intrinsic motivation, the most self-determined type of motivation, was predicted by all three factors: perceived autonomy, perceived affiliation, and perceived ability. The above pattern echoes Deci, Eghrari, Patrick, and Leone's (1994) experimental study where zero or one supporting factor lead to participants' introjected internalization whereas two or three supporting factors resulted in participants' integrated internalization. This study shed important light on online learner support: multiple strategies should be integrated into the online learning environment to ensure that all three types of learner support are addressed. With sufficient supports of autonomy, affiliation, and ability, students are more likely to internalize goals and values of online courses and become self-determined online learners.

Similar to motivation variables, the relative salience of perceived autonomy, perceived affiliation, and perceived ability varied by categories of learning outcomes. Perceived autonomy was the most salient factor predicting student engagement. Perceived ability accounted most for online students' perceived learning and achievement. Perceived affiliation best explained online learner's course satisfaction. Moreover, addressing student autonomy, affiliation and ability are more likely to enhance online learners' perceived learning, expected grade, and course satisfaction, judging from the percentage that significant factors explained the variance of outcome variables. The results mentioned directly above provide a reference for online instructors to align instructional strategies with desired outcomes, and to prioritize resources to render support. For instance, if the primary goal of an online instructor is to promote students' perceived learning, he or she can lay more emphasis on supporting student ability. Alternatively, if the instructor intends to enhance student satisfaction toward the online course, he or she can allocate more resources to promote social interactions. 
This study sheds light on online learner support. Online students' immediate context has significant impact on their motivation and learning outcomes. Online learning practitioners, including administrators, instructors, teaching assistants, and technical support personnel all play important roles in supporting online learners (Chen \& Branch, 2009). They should work hand in hand to create a warm and supportive learning environment. They should be aware that perceived autonomy, affiliation, and ability affect significantly but differently on online students' motivation and learning outcomes. To ensure online students' self-determined motivation, supports of all three factors should be addressed in the online learning context. Online learning practitioners can tacitly allocate available resources to support learner autonomy, affiliation, and ability, and align instructional support strategies with intended learning outcomes.

This study is exploratory in nature. We acknowledge the limitation of conducting multiple regression several times within a single study that to some extent inflates Type I error. We also acknowledge the possibility that motivation mediates between factors and learning consequences. Future studies may adopt more rigorous statistical approaches such as canonical analysis or structural equation modeling, and further explore the hierarchical relationships among factors, motivation, and learning consequences.

Despite the abovementioned limitations, this study serves as one of the earliest studies that explore the relative salience of autonomy, affiliation, and ability in an online learning environment. Results of this study have provided implications for online learner support. We hope that this study can inspire more studies on factors that influence online learner motivation and learning outcomes, as well as support strategies that promote learner autonomy, affiliation and ability. We believe that such endeavors will help online learners become more assured and self-determined, allowing them more enjoyment and satisfaction with their online learning journey.

\section{References}

1 Alavi, M. (1994). Computer-mediated collaborative learning: An empirical evaluation. MIS Quarterly, 18, 159-174.

2 Allen, E., \& Seaman, J. (2006). Making the grade: Online education in the United States,2006. Available from: http://www.sloan-c.org/publications/survey/pdf/ making_the_grade.pdf

3 Armatas, C., Holt, D., \& Rice, M. (2003). Impacts of an online-supported, resource-based learning environment: Does one size fit all? Distance Education, 24(2), 141-158.

4 Bertalanffy, L. V. (1972). The history and status of general systems theory. The Academy of Management Journal, 15(4), 407-426.

5 Brande, L. V. D. (1994). Flexible and distance learning. Chichester, England: John Wiley \& Sons.

6 Carr, S. (2000). As distance education comes of age, the challenge is keeping the students. Chronicle of Higher Education, 46(23), A39-A41.

7 Chen, K.C., \& Branch, R. M. (2009). Autonomy, affiliation, and ability: Instructional support strategies that motivate online students. Paper presented at the 2009 AECT International Convention, Louisville, KY. 
8 Chou, S. W., \& Liu, C. H. (2005). Learning effectiveness in a Web-based virtual learning environment: A learner control perspective. Journal of Computer Assisted Learning, 21(1), 65-76.

9 Collins, M. P., \& Berge, Z. L. (1995). Introduction: Computer-mediated communications and the online classroom in higher education. In M. P. Collins \& Z L. Berge (Eds.), Computer mediated communication and the online classroom: Volume II (pp. 1-10). Cresskill, NJ: Hampton Press.

10 Conrad, D. L. (2002). Engagement, excitement, anxiety, and fear: Learners' experiences of starting an online course. American Journal of Distance Education, 16(4), 205-226.

11 Dabbagh, N., \& Bannan-Ritland, B. (2005). Online learning: Concepts, strategies, and application. Upper Saddle River, NJ: Merrill.

12 Davis, F., Bagozzi, R., \& Warshaw, P. (1989). User acceptance of computer technology: A comparison of two theoretical models. Management Science, 35(8), 982-1003.

13 Deci, E. L., Eghrari, H., Patrick, B. C., \& Leone, D. (1994). Facilitating internalization: The self-determination theory perspective. Journal of Personality, 62, 119-142.

14 Deci, E. L., \& Ryan, R. M. (1985). Intrinsic motivation and self-determination in human behavior. New York: Plenum.

15 Deci, E. L., \& Ryan, R. M. (2002). Handbook of self-determination research. Rochester, NY: University of Rochester Press.

16 Dede, C. (1996). Emerging technologies in distance education for business. Journal of Education for Business, 71(4), 197-205.

17 Dennen, V. P., Darabi, A. A., \& Smith, L. J. (2007). Instructor-learner interaction in online courses: The relative perceived importance of particular instructor actions on performance and satisfaction. Distance Education, 28(1), 65-79.

18 Drennan, J., Kennedy, J., \& Pisarki, A. (2005). Factors affecting student attitudes toward flexible online learning in management education. Journal of Educational Research, 98(6), 331-338.

19 Galusha, J. M. (1997). Barriers to learning in distance education. Interpersonal Computing and Technology Journal, 5 (3-4), 6-14.

20 Gao, T., \& Lehman, J. D. (2003). The effects of different levels of interaction on the achievement and motivational perceptions of college students in a Web-based learning environment. Journal of Interactive Learning Research, 14(4), 367-386.

21 Gomez Alvarez, L. D. C. (2005). Seven principles of good teaching practice: Predictors of perceived learning and satisfaction with online courses. Unpublished doctoral dissertation, The University of Nebraska, Lincoln, NE.

22 Hao, Y. W. (2004). Students' attitudes toward interaction in online learning: Exploring the relationship between attitudes, learning styles, and course satisfaction. Unpublished doctoral dissertation, The University of Texas at Austin, Austin, TX.

23 Hara, N., \& Kling, R. (2000). Students' frustrations with a Web-based distance education course: An ethnographic study of participants' experiences. Available from: http://www.firstmonday.org/issues/issue4_12/hara/index.html

24 Howland, J. L., \& Moore, J. L. (2002). Student perceptions as distance learners in Internet-based courses. Distance Education, 23(2), 183-195. 
25 Jang, S. J. (2008). The effects of integrating technology, observation and writing into a teacher education method course. Computers \& Education, 50(3), 853-865.

26 Keller, J. M. (1999). Motivation in cyber learning environments. International Journal of Educational Technology, 1, 7-30.

27 Kim, K. J., Liu, S., \& Bonk, C. J. (2005). Online MBA students' perceptions of online learning: Benefits, challenges, and suggestions. Internet \& Higher Education, 8(4), 335-344.

28 Kreijns, K., Kirschner, P. A., \& Jochems, W. (2003). Identifying the pitfalls for social interaction in computer-supported collaborative learning environments: A review of the research. Computers in Human Behavior, 19(3), 335-353.

29 Lapadat, J. (2002). Written interaction: A key component in online learning. Journal of Computer-Mediated Communication 7(4). Available from: http:// www.ascusc.org/jcmc/vol7/issue4/lapadat.html

30 Lim, C. K. (2001). Computer self-efficacy, academic self-concept, and other predictors of satisfaction and future participation of adult distance learners. The American Journal of Distance Education, 15(2), 41-51.

31 Locatis, C., \& Weisberg, M. (1997). Distributed learning and the Internet. Contemporary Education, 68 (2), 100-103.

32 Marks, R. B., Sibley, S. D., \& Arbaugh, J. B. (2005). A structural equation model of predictors for effective online learning. Journal of Management Education, 29(4), 531-563.

33 Mayer, R. E., \& Moreno, R. (2003). Nine ways to reduce cognitive load in multimedia learning. Educational Psychologist, 38(1), 43-52.

34 Moore, M. G. (1989). Three types of interaction. The American Journal of Distance Education, 3(2), 1-6.

35 Moore, M. G. (1993). Theory of transactional distance. In D. Keegan (Ed.), Theoretical principles of distance education (pp. 22-38). New York: Routledge.

36 Morrison, M., Sweeney, A., \& Heffernan, T. (2004). Learning styles of on-campus marketing students: The challenge for marketing educators. Journal of Marketing Education, 25, 208-217.

37 Motteram, G., \& Forrester, G. (2005).. Becoming an online distance learner: What can be learned from students' experiences of induction to distance programmes? Distance Education, 26(3), 281-298.

38 Olgren, C. H. (1998). Improving learning outcomes: The effects of learning strategies and motivation. In C. C. Gibson (Ed.), Distance learners in higher education (pp. 79-96). Madison, WI: Atwood.

39 Peltier, J. W., Schibrowsky, J. A., \& Drago, W. (2007). The interdependence of the factors influencing the perceived quality of the online learning experience: A causal model. Journal of Marketing Education, 29(2), 140-153.

40 Pintrich, P. R., \& Schunk, D. H. (2002). Motivation in education: Theory, research, and applications (2nd ed.). Upper Saddle River, NJ: Merrill Prentice Hall.

41 Reed, A. (2000). Computer-mediated communication (CMC) and the traditional classroom. Teaching with Technology Today, 5(6). Available from: http:// www.uwsa.edu/ttt/reed.htm

42 Riel, M. \& Harasim, L. (1994). Research perspectives on network learning. Journal of Machine-Mediated Learning, 4(2-3), 91-114. 
43 Rovai, A. P. (2003). In search of higher persistence rates in distance education online programs. Internet and Higher Education, 6(1), 1-16.

44 Ryan, R. M., \& Deci, E. L. (2000). Self-determination theory and the facilitation of intrinsic motivation, social development, and well-being. American Psychologist, $55,68-78$.

45 Ryan, R. M., \& Deci, E. L. (2002). Overview of self-determination theory: An organismic dialectical perspective. In E. L. Deci \& R. M. Ryan (Eds.), Handbook of self-determination research (pp. 3-33). Rochester, NY: University of Rochester Press.

46 Song, L., Singleton, E. S., Hill, J. R., \& Koh, M. H. (2004). Improving online learning: Student perceptions of useful and challenging characteristics. Internet \& Higher Education, 7(1), 59-70.

47 South, S. E. (2006). Contributing factors to engagement in online learning environments: The relationship between sense of community and participation. Unpublished doctoral dissertation, University of Arizona, Tucson, AZ.

48 Standage, M., Duda, J. L., \& Ntoumanis, N. (2003). A model of contextual motivation in physical education: Using constructs from self-determination theory and achievement goals to predict physical activity intentions. Journal of Educational Psychology, 91, 97-110.

49 Tait, A. (2003). Rethinking learner support in the Open University UK. In A. Tait \& R. Mills (Eds.), Rethinking learner support in distance education: Change and continuity in an international context (pp. 185-197). London: Routledge.

50 Thompson, L. F., Meriac, J. P., \& Cope, J. G. (2002). Motivating online performance: The influences of goal setting and Internet self-efficacy. Social Science Computer Review, 20(2), 149-160.

51 Tu, C. H. (2002). The impacts of text-based CMC on online social presence. Journal of Interactive Online Learning, 1(2), 1-24.

52 Vallerand, R. J., Pelletier, L. G., Blais, M. R., Brie`re, N. M., Sene'cal, C. B., \& Vallie'res, E. F. (1992). The Academic Motivation Scale: A measure of intrinsic, extrinsic, and amotivation in education. Educational and Psychological Measurement, 52(4), 1003-1019.

53 Vonderwell, S., \& Zachariah, S. (2005). Factors that influence participation in online learning. Journal of Research on Technology in Education, 38(2), 213-230.

54 Wegerif, R. (1998). The social dimension of asynchronous learning networks. Journal of Asynchronous Learning Networks, 2(1), 34-49.

55 Williams, M. D. (1996). Learner-control and instructional technologies. In D. H. Jonassen (Ed.), Handbook of research for educational communications and technology. New York: Simon \& Schuster Macmillan.

56 Xie, K., Debacker, T. K., \& Ferguson, C. (2006). Extending the traditional classroom through online discussion: The role of student motivation. Journal of Educational Computing Research, 34(1), 67-89.

57 Yang, C. C., Tsai, I. C., Kim, B., Cho, M. H., \& Laffey, J. M. (2006). Exploring the relationships between students' academic motivation and social ability in online learning environments. Internet \& Higher Education, 9(4), 277-286. 